\section{APF530 (granisetron injection extended-release) in a three-drug regimen for delayed CINV in highly emetogenic chemotherapy}

\author{
Ian D Schnadig*, ${ }^{* 1}$, Richy Agajanian², Christopher Dakhil ${ }^{3}$, Nashat Y Gabrail ${ }^{4}$, \\ Robert E Smith Jr ${ }^{5}$, Charles Taylor ${ }^{6}$, Sharon T Wilks ${ }^{7}$, Lee S Schwartzberg ${ }^{8}$, \\ William Cooper ${ }^{9}$, Michael C Mosier ${ }^{10}$, J Yvette Payne ${ }^{11}$, Michael J Klepper ${ }^{12}$ \\ \& Jeffrey $L$ Vacirca ${ }^{13}$
}

\begin{abstract}
Aim: APF530, extended-release granisetron, provides sustained release for $\geq 5$ days for acute- and delayed-phase chemotherapy-induced nausea and vomiting (CINV). We compared efficacy and safety of APF530 versus ondansetron for delayed CINV after highly emetogenic chemotherapy (HEC), following a guideline-recommended three-drug regimen. Methods: HEC patients received APF530 500 mg subcutaneously or ondansetron $0.15 \mathrm{mg} /$ $\mathrm{kg}$ intravenously, with dexamethasone and fosaprepitant. Primary end point was delayedphase complete response (no emesis or rescue medication). Results: A higher percentage of APF530 versus ondansetron patients had delayed-phase complete response $(p=0.014)$. APF530 was generally well tolerated; treatment-emergent adverse event incidence was similar across arms, mostly mild-to-moderate injection-site reactions. Conclusion: APF530 versus the standard three-drug regimen provided superior control of delayed-phase CINV following HEC. ClinicalTrials.gov: NCT02106494.
\end{abstract}

First draft submitted: 11 February 2016; Accepted for publication: 4 March 2016;

Published online: 21 March 2016

Chemotherapy-induced nausea and vomiting (CINV) is detrimental to patients' quality of life and can lead to chemotherapy dose reductions or delays [1,2]. Chemotherapy is categorized by emetogenicity [3]. Treatment guidelines from the American Society of Clinical Oncology (ASCO), Multinational Association of Supportive Care in Cancer, and National Comprehensive Care Network (NCCN) recommend a three-drug antiemetic regimen in patients receiving highly emetogenic chemotherapy (HEC), comprising a 5-hydroxytryptamine type $3\left(5-\mathrm{HT}_{3}\right)$ receptor antagonist (RA), dexamethasone and a NK-1 RA. Guideline-recommended 5-HT 3 RAs for HEC include granisetron, ondansetron, palonosetron and dolasetron [3]. When administered intravenously (iv.) on the day of chemotherapy, these agents do not confer sufficient duration of action to provide CINV control

'Compass Oncology, US Oncology Research, Tualatin, OR, USA

${ }^{2}$ The Oncology Institute of Hope \& Innovation, Whittier, CA, USA

${ }^{3}$ Cancer Center of Kansas, Wichita, KS, USA

${ }^{4}$ Gabrail Cancer Center, Canton, OH, USA

${ }^{5}$ South Carolina Oncology Associates, Columbia, SC, USA

${ }^{6}$ Tulsa Cancer Institute, Tulsa, OK, USA

${ }^{7}$ Cancer Care Centers of South Texas, San Antonio, TX, USA

${ }^{8}$ The West Clinic, Memphis, TN, USA

${ }^{9}$ TFS, Princeton, NJ, USA

${ }^{10}$ EMB Statistical Solutions, LLC, Overland Park, KS, USA

"Heron Therapeutics, Inc., San Diego, CA, USA (at time of study)

${ }^{12}$ Drug Safety Navigator, LLC, Durham, NC, USA

${ }^{13}$ North Shore Hematology Oncology, East Setauket, NY, USA

*Author for correspondence: Tel.: +1 503692 2032; Fax: +1 503692 4450; ian.schnadig@usoncology.com

\section{KEYWORDS}

- chemotherapy-induced nausea and vomiting $(\mathrm{CINV}) \bullet$ extended-release granisetron $\bullet$ highly emetogenic chemotherapy (HEC) 
as effectively in the delayed phase (24-120 h) as in the acute phase $(0-24 \mathrm{~h})$ [4-8]. This has led to overall higher rates of CINV, particularly following HEC [1,5]. To date, no Phase III efficacy studies have demonstrated superiority in a primary end point of one $5-\mathrm{HT}_{3} \mathrm{RA}$ over another in delayed-phase CINV following HEC with an NK-1 RA [9-14]. New approaches are needed to prevent delayed-phase CINV following HEC.

APF530, a novel, extended-release granisetron formulation, provides sustained release of therapeutic concentrations for $\geq 5$ days. APF530 uses a viscous bioerodible Biochronomer ${ }^{\circledR}$ (Heron Therapeutics, Inc., Redwood City, CA, USA) tri(ethylene glycol) poly(orthoester) (TEGPOE) formulation for subcutaneous (sc.) injection into the abdomen or upper arm [15-17]. In Phase I and II trials, APF530 was well tolerated among healthy volunteers and patients receiving moderately emetogenic chemotherapy (MEC) or HEC, with sustained therapeutic granisetron concentrations over $168 \mathrm{~h}[17,18]$. Results of a large Phase III trial with a primary efficacy end point of complete response (CR; no emetic episodes or rescue medication use) demonstrated APF530 noninferiority to iv. palonosetron $(0.25 \mathrm{mg})$ in controlling acute CINV associated with MEC or HEC and delayed CINV associated with MEC [19,20]. APF530 demonstrated sustained prevention of acute and delayed CINV when administered over multiple MEC or HEC cycles [21]. Numerically higher CR rates with APF530 versus palonosetron in acute and delayed CINV following HEC suggested a need for further investigation in this setting $[19,20]$. Primary and secondary end points of a Phase III trial comparing palonosetron with ondansetron in acute- and delayed-phase CR following HEC found palonosetron to be noninferior to ondansetron in the acute phase, with no significant between-treatment differences in delayed and overall phases [10].

This Phase III trial (MAGIC Trial) evaluated efficacy and safety of APF530 versus ondansetron, both administered with fosaprepitant and dexamethasone, for prevention of CINV following HEC. This is the first Phase III, registrational, three-drug versus three-drug regimen efficacy trial comparing $5-\mathrm{HT}_{3} \mathrm{RAs}$ in the presence of an NK-1 RA and dexamethasone for CINV prevention. Previous registrational trials evaluating antiemetics as part of a three-drug regimen in HEC (i.e., aprepitant, netupitant and palonosetron [NEPA], rolapitant) involved two-drug regimen comparator arms only $\left(5-\mathrm{HT}_{3}\right.$ RA and dexamethasone) - inconsistent with contemporary guidelines [22,23].

\section{Materials \& methods}

\section{- Study design}

This prospective, randomized, double-blind, double-dummy, parallel-group, multicenter Phase III trial was conducted at 77 centers across the USA, approved by each investigational site's Institutional Review Board, and conducted according to the Declaration of Helsinki.

The following organizations were contracted to assist in conducting the trial: Accelovance, Inc., MD, USA served the function of the contract research organization and all aspects of the trial management including central clinical laboratory evaluations and study drug management, and data management; EMB Statistical Solutions LLC, KS, USA, and TFS, NJ, USA planned and conducted data analysis.

\section{- Patients}

Eligible men or women were $18-80$ years of age with a histologically or cytologically confirmed malignancy, scheduled to receive singleday HEC, and entering the first cycle of their regimen. Chemotherapy emetogenicity was classified by 2011 ASCO criteria, which reclassified anthracycline-cyclophosphamide-based regimens as HEC. Patients could receive standardized dexamethasone doses and had a life expectancy of $\geq 6$ months, Eastern Cooperative Oncology Group performance status (ECOG PS) of $0-1$, and adequate bone marrow, kidney and liver function. Female patients were not pregnant and used contraception on study. All patients provided written informed consent. Ethnicity data were collected to ensure comparability of study arms, and were determined by asking patients at the screening visit.

Exclusion criteria included known hypersensitivity to any $5-\mathrm{HT}_{3} \mathrm{RA}$, history or presence of a clinically significant abnormal 12-lead electrocardiogram (ECG) or ECG with corrected QT interval by Bazett's correction $>450 \mathrm{~ms}$ in men and $>470 \mathrm{~ms}$ in women, PR interval $>240 \mathrm{~ms}$, QRS complex $>110 \mathrm{~ms}$ or history or family history of QT interval prolongation, other clinically significant cardiac disease or electrolyte disturbance. Patients must not have had ongoing vomiting, retching or nausea or history of anticipatory nausea and vomiting. Patients may not have taken $5-\mathrm{HT}_{3}$ RAs, phenothiazines, 
benzamides, domperidone, cannabinoids or NK-1 RAs within 7 days before chemotherapy initiation.

\section{- Procedures}

The APF530 arm received APF530 500 mg sc. (10 mg granisetron) and ondansetron (saline) placebo iv. on day 1 . The ondansetron arm received ondansetron $0.15 \mathrm{mg} / \mathrm{kg}$ iv. (maximum $16 \mathrm{mg}$ ) and APF530 placebo sc. (containing Biochronomer TEG-POE vehicle), day 1. All received concomitant fosaprepitant $150 \mathrm{mg}$ iv. and dexamethasone $12 \mathrm{mg}$ iv., day 1, and dexamethasone $8 \mathrm{mg}$ orally once daily, day 2 , and twice daily, days 3-4. A topical anesthetic was applied to the injection site (i.e., abdomen or upper arm) before APF530 $500 \mathrm{mg}$ or placebo subcutaneous injection. On day 1 , all study medications were to be administered $\geq 30 \mathrm{~min}$ before chemotherapy start. Rescue medication was allowed at physician's discretion.

The study included these visits: screening (day -21 to day -1), baseline/day 1 (days 2-5, self-reporting by patient), day 6 , and final safety follow-up on the day of patients' next chemotherapy administration. Patients received a diary on day 1 to record nausea, retching and vomiting episodes and rescue medication use, daily to day $6(120 \mathrm{~h})$ after chemotherapy.

\section{- Outcomes}

The primary objective was to demonstrate superiority of APF530 $500 \mathrm{mg}$ sc. versus ondansetron $0.15 \mathrm{mg} / \mathrm{kg}$ iv., as part of the current guideline-recommended three-drug regimen, in preventing delayed-phase CINV following HEC. End point definitions are summarized in Supplementary Table 1. The primary end point was delayed-phase (24-120 h) complete response (CR: no emetic episodes [vomiting or retching], no rescue medications). Besides the primary end point, a prespecified analysis of delayed-phase CR by randomization strata was done (planned use of cisplatin-based regimens $\left[\geq 50 \mathrm{mg} / \mathrm{m}^{2}\right.$, yes $/$ no]; see Supplementary Information). Secondary end points were overallphase CR and rate of no emetic episodes; and delayed-phase and overall-phase complete control (CC: CR, no more than mild nausea). Other end points are summarized in the Supplementary Information. Primary, secondary and selected other end points are reported. Supplementary Information detail the safety assessments. End points not reported include acute delayed- and overall-phase total response (TR); rate, number and control of emesis; nausea severity; and health-related quality of life.

\section{- Statistical analyses}

The study was designed to demonstrate the superiority of the APF530 $500 \mathrm{mg}$ regimen versus ondansetron $0.15 \mathrm{mg} / \mathrm{kg}$ regimen in delayedphase CR. For powering the study, the superiority design assumed a $65 \%$ CR rate in the ondansetron arm, and at least a $75 \%$ CR rate in the APF530 arm (based on historical CR rates [24]), using a two-sided hypothesis test with $\alpha=0.05$. A planned sample size of approximately 1000 , with data from $\geq 880$ evaluable patients, was required to provide $90 \%$ statistical power for comparison. Efficacy analyses were performed on the modified intent-to-treat (mITT) population, comprising all randomized patients who received study drug and an HEC regimen and had postbaseline efficacy data. Safety analyses were based on the safety population, comprising all randomized patients who received study drug.

Qualitative variable analysis used a CochranMantel-Haenszel (CMH) $\chi^{2}$ test controlled by randomization strata. For ordinal qualitative variables, such as frequency of nausea episodes, this test used modified ridit scores. With rare exceptions due to mis-stratification, the cisplatin 'yes' stratum included patients who received cisplatin-based regimens with $\geq 50 \mathrm{mg} / \mathrm{m}^{2}$; the cisplatin 'no' stratum included patients on noncisplatin-based regimens (cisplatin doses $<50 \mathrm{mg} / \mathrm{m}^{2}$ were not considered HEC; patients prescribed such low-dose cisplatin were ineligible). A strata-adjusted Wald-type 95\% CI for difference in proportions computation followed the $\mathrm{CMH}$ weighting scheme. Statistical tests were two-sided with a significance level of $\alpha=0.05$. To control for type I error, the significance of tests for four secondary end points was adjusted using the Hochberg method [25]. Kaplan-Meier estimates were provided for time-to-event end points, and log-rank test used for treatment comparison. Adverse events were summarized descriptively (Supplementary Table 2). This trial is registered at ClinicalTrials.gov, NCT02106494.

\section{Results}

Between 31 March 2014, and 15 May 2015, 942 patients were randomized across 77 US centers (471 APF530, 471 ondansetron) and constituted the intent-to-treat (ITT) population; 915 (456 APF530, 459 ondansetron) received study drug 
RESEARCH ARTICLE Schnadig, Agajanian, Dakhil et al.

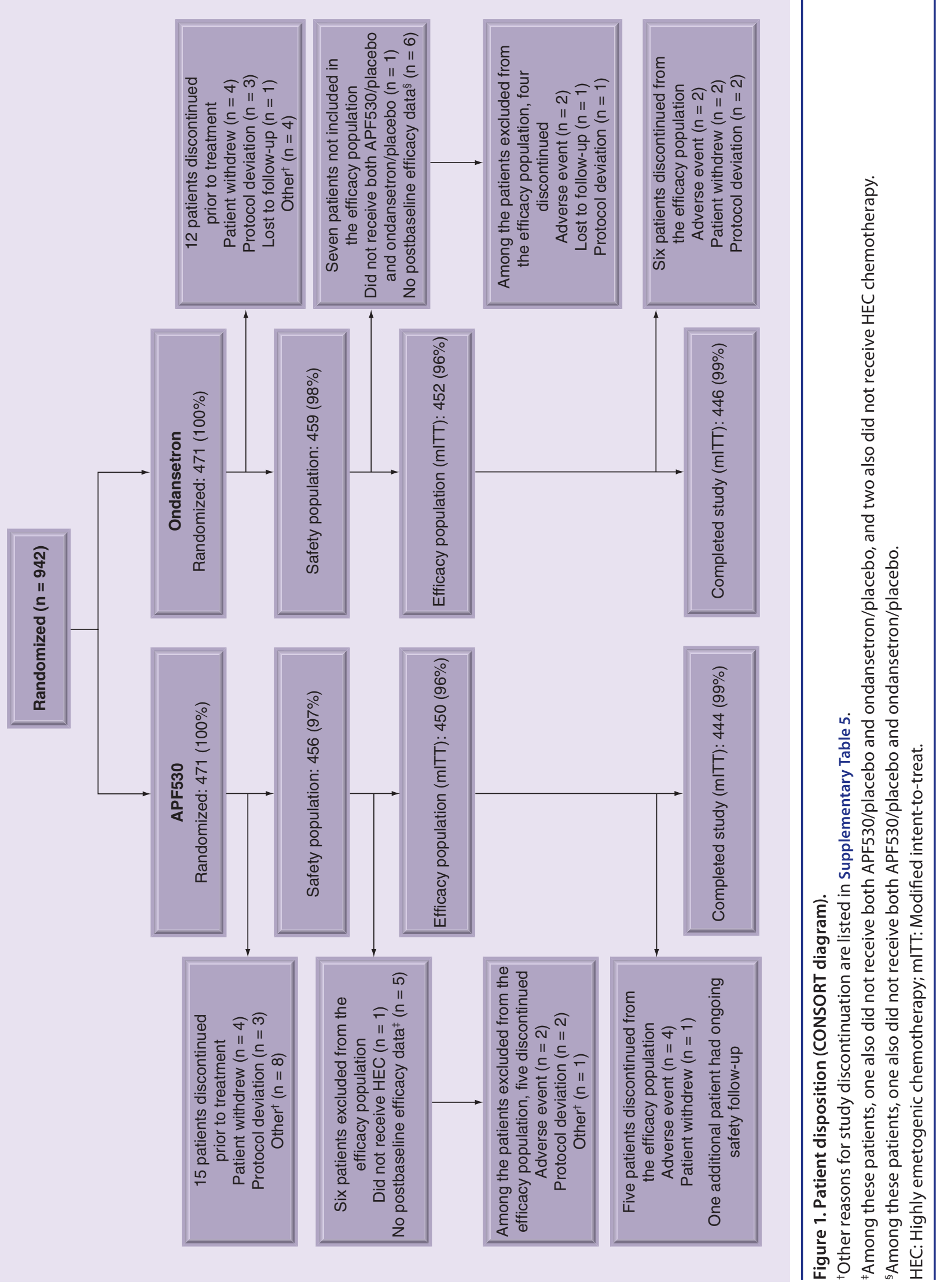


and were in the safety analysis. The 902 mITT patients (450 APF530, 452 ondansetron) comprised all who received study drug and HEC and had postbaseline efficacy data (Figure 1).

Patient demographics and baseline clinical characteristics were well balanced between treatment arms (Table 1). Mean patient age was approximately 55 years, most were women (358/450, 79.6\% APF530; 373/452, 82.5\% ondansetron), and most had an ECOG PS of $0(342 / 450$, 76.0\% APF530; 336/452, 74.3\% ondansetron). The most common chemotherapy regimens were anthracycline and cyclophosphamide (AC) based (291/450, 64.7\% APF530; 298/452, 65.9\% ondansetron) and cisplatin based (125/450, 27.8\% APF530; 126/452, 27.9\% ondansetron) (Supplementary Table 3). The most common reasons for discontinuation were adverse events, protocol violations, consent withdrawal and loss to follow-up; between-arm frequencies were generally balanced (Supplementary Tables 4 \& 5).
For the primary end point, the proportion of patients with delayed-phase CR was significantly greater with the APF530 (291/450, 64.7\%) versus ondansetron regimen $(256 / 452,56.6 \%)$; the absolute treatment difference was $8.0 \%$ (95\% CI: 1.7-14.4; p = 0.014) (Figure 2A).

Within the cisplatin stratum, delayed-phase CR rates were $65.3 \%(81 / 124)$ with the APF530 regimen and $54.7 \%(70 / 128)$ with the ondansetron regimen; the absolute treatment difference was $10.6 \%$ (95\% CI: -1.4-22.7). Delayed-phase $\mathrm{CR}$ rates within the noncisplatin stratum were $64.4 \%(210 / 326)$ and $57.4 \%(186 / 324)$ in the APF530 and ondansetron arms, respectively (absolute treatment difference: 7.0\%; 95\% CI: $-0.5-14.5)$.

For secondary end points, overall-phase CR was numerically higher with the APF530 $(263 / 450,58.4 \%)$ versus ondansetron regimen (239/452, 52.9\%), but not statistically significantly (treatment difference: $5.6 \%$; 95\% CI:

\section{Table 1. Demographics and baseline clinical characteristics (modified intent-to-treat} population).

\begin{tabular}{|c|c|c|}
\hline Variable & APF530 $(n=450)$ & Ondansetron $(n=452)$ \\
\hline \multicolumn{3}{|l|}{ Age (year): } \\
\hline - Mean (SD) & $55.7(11.75)$ & $55.6(11.94)$ \\
\hline$-\geq 65 ; n(\%)$ & $117(26.0)$ & $118(26.1)$ \\
\hline \multicolumn{3}{|l|}{ Gender; n (\%): } \\
\hline - Male & $92(20.4)$ & 79 (17.5) \\
\hline - Female & $358(79.6)$ & $373(82.5)$ \\
\hline \multicolumn{3}{|l|}{ Ethnicity; n (\%): } \\
\hline - Not Hispanic/Latino & $377(83.8)$ & $384(85.0)$ \\
\hline - Hispanic/Latino & $72(16.0)$ & $68(15.0)$ \\
\hline - Unknown & $1(0.2)$ & $0(0)$ \\
\hline \multicolumn{3}{|l|}{ Race; n (\%): } \\
\hline - White & $368(81.8)$ & $372(82.3)$ \\
\hline \multicolumn{3}{|l|}{ BMI $\left(\mathrm{kg} / \mathrm{m}^{2}\right)$ : } \\
\hline$-\mathrm{n}$ & 436 & 440 \\
\hline - Mean (SD) & $29.72(6.917)$ & $29.55(6.872)$ \\
\hline \multicolumn{3}{|c|}{$\begin{array}{l}\text { Planned cisplatin-based chemotherapy regimen } \\
\geq 50 \mathrm{mg} / \mathrm{m}^{2} ; \mathrm{n}(\%):\end{array}$} \\
\hline - Yes & $124(27.6)$ & $128(28.3)$ \\
\hline$-\mathrm{No}$ & $326(72.4)$ & $324(71.7)$ \\
\hline \multicolumn{3}{|l|}{ ECOG PS; n (\%): } \\
\hline-0 & $342(76.0)$ & $336(74.3)$ \\
\hline-1 & $105(23.3)$ & $114(25.2)$ \\
\hline - Unknown & $3(0.7)$ & $2(0.4)$ \\
\hline \multicolumn{3}{|l|}{ Currently drink alcohol; n (\%): } \\
\hline - Any & $170(37.8)$ & $167(36.9)$ \\
\hline$-\geq 8$ drinks/week & $19(4.2)$ & $15(3.3)$ \\
\hline Currently smoke tobacco; n (\%) & 70 (15.6) & $72(15.9)$ \\
\hline
\end{tabular}




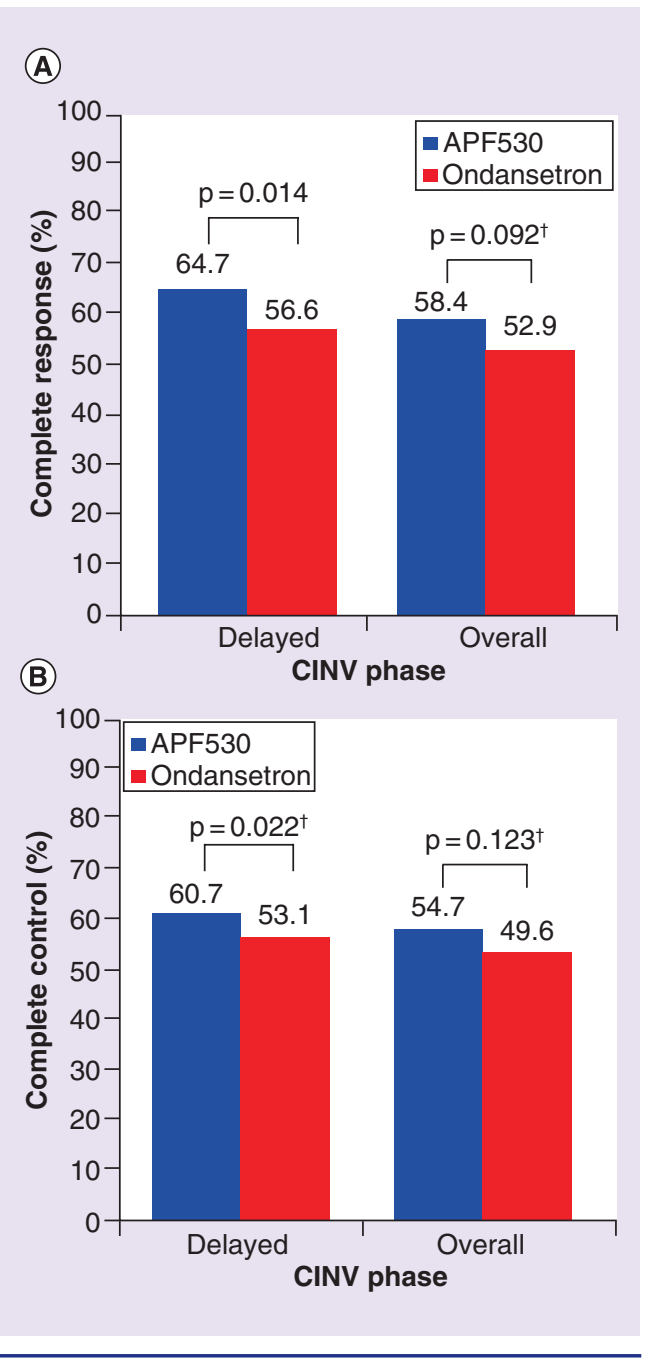

Figure 2. Complete response (A) and complete control (B) rates during delayed and overall phases. Primary efficacy end point was delayedphase complete response.

p-values are based on Cochran-Mantel-Haenszel

$\chi^{2}$ test controlled by use of cisplatin-based regimen ( $\geq 50 \mathrm{mg} / \mathrm{m}^{2}$ [yes $/ \mathrm{no}$ ]).

${ }^{\dagger} \mathrm{p}$-values for secondary end points are unadjusted for multiple testing. See Table 2 for Hochberg-adjusted $p$-values.

CINV: Chemotherapy-induced nausea and vomiting.

-0.9-12.1; unadjusted $\mathrm{p}=0.092)$. Consistent with delayed-phase CR findings, a greater proportion of patients on the APF530 (273/450, $60.7 \%)$ versus ondansetron regimen $(240 / 452$, $53.1 \%)$ had delayed-phase CC, with a treatment difference of 7.6\% (95\% CI: 1.1-14.0; unadjusted $\mathrm{p}=0.022)$. Overall-phase $\mathrm{CC}$ rates were numerically higher with the APF530 versus ondansetron regimen $(246 / 450,54.7 \%$ vs 224/452, 49.6\%; unadjusted $\mathrm{p}=0.123$ ) (Figure 2A \& B). Rates of no emetic episodes in APF530 and ondansetron arms were $82.2 \%$ $(370 / 450)$ and $79.2 \%(358 / 452)$, respectively (unadjusted $\mathrm{p}=0.254$ ). Controlling for overall type I error (Hochberg model) resulted in no secondary end points achieving statistical significance (Table 2).

For other end points, acute-phase CR and CC are shown in Supplementary Table 6. The proportion of patients with treatment failure (Figure 3A) was consistently higher with the ondansetron versus APF530 regimen over the study course, although not statistically significantly $(\mathrm{p}=0.095)$.

Rates of no nausea by study phase were numerically higher with the APF530 regimen in delayed $(p=0.099)$ and overall phases $(\mathrm{p}=0.138)$, although not statistically significantly (Supplementary Table 7). The proportion of patients who experienced nausea was generally higher across the study period with the ondansetron versus APF530 regimen (Figure 3B).

Patient-reported satisfaction with nausea and vomiting control showed a significant difference favoring the APF530 versus ondansetron regimen in the delayed phase $(\mathrm{p}=0.040)$ and was numerically higher, although not statistically significantly, in the overall phase $(\mathrm{p}=0.199)$ (Supplementary Table 8).

A significantly greater proportion of patients receiving the APF530 versus ondansetron regimen reported no rescue medication use in delayed (316/445, $71.0 \%$ vs $280 / 443,63.2 \%$; $\mathrm{p}=0.013)$ and overall phases $(295 / 445,66.3 \%$ vs $264 / 443,59.6 \% ; \mathrm{p}=0.038)$. Time to first rescue medication use was significantly longer with the APF530 versus ondansetron regimen $(\mathrm{p}=0.049)$.

A post hoc, hypothesis-generating analysis of nausea frequency indicated that patients receiving the APF530 versus ondansetron regimen experienced less frequent nausea ( $0-2$ vs $\geq 3$ episodes) in delayed $(\mathrm{p}=0.032)$ and overall phases $(\mathrm{p}=0.048)$ (Table 3$)$.

A similar proportion of patients in the APF530 and ondansetron arms experienced $\geq 1$ treatment-emergent adverse event (TEAE) (413/456, 90.6\% APF530; 411/459, 89.5\% ondansetron), the majority of which were mild to moderate (Table 4). The most common TEAEs were constipation, fatigue, headache and ISRs. Severe (grade $\geq 3$ ) TEAEs were reported in $19.5 \%(89 / 456)$ and $19.4 \%(89 / 459)$ of patients 
receiving APF530 and ondansetron regimens, respectively. Excluding ISRs, only 1.8\% (8/456) and $0.9 \%$ (4/459) of APF530 and ondansetron patients experienced severe treatment-related TEAEs. TEAEs led to study withdrawal in 1.3\% $(6 / 456)$ and $0.7 \%$ (3/459) of patients in APF530 and ondansetron arms, respectively; none was considered study drug related.

A similar proportion of APF530 and ondansetron patients experienced $\geq 1$ ISR (282/456, 61.8\% APF530; 273/459, 59.5\% ondansetron), all conservatively considered treatment related. Between-treatment-arm differences in ISR frequency were minimal; most were mild or moderate. The most common ISRs in APF530 and ondansetron arms were injection-site bruising (191/456, 41.9\% APF530; 154/459, 33.6\% ondansetron) and injection-site pain (141/456, 30.9\% APF530; 163/459, 35.5\% ondansetron). Injection-site bruising was the most common severe ISR in both arms (21/456, 4.6\% APF530; 25/459, 5.4\% ondansetron). No grade 4 ISRs were reported in either arm. Most ISRs appeared 1-3 days postinjection; the most common delayed-onset ISRs (>8 days) were nodules. Most ISRs resolved (260/282, 92.2\% APF530; 260/273, 95.2\% ondansetron); reports of ongoing ISRs may be due to short follow-up. Severity of most ISRs was determined by prespecified criteria based on size and appearance only, not functional impairment (Supplementary Figure 2 \& Supplementary Table 2).

Treatment-emergent serious adverse events (SAEs), reported in $6.1 \%(28 / 456)$ and $3.5 \%$ (16/459) of patients in APF530 and ondansetron arms, respectively, were considered isolated events with no distinct pattern. Treatmentrelated SAEs were reported by two APF530 patients (injection-site infection, atrial fibrillation) and one ondansetron patient (dehydration). Overall, five safety-population patients died on study (three APF530, two ondansetron); all deaths were due to underlying disease and not considered study drug related.

Sporadic and transient abnormalities in laboratory values, vital signs and weight were noted; no adverse or clinically significant treatment-related trends were identified in either arm.

\section{Discussion}

This Phase III study met its primary end point, demonstrating that APF530 provided superior control of delayed-phase CINV following HEC versus ondansetron, both in a recommended three-drug regimen with an NK-1 RA and dexamethasone. Although the study was not powered to detect differences in acute or overall-phase CINV, the APF530 regimen was associated with numerically, but not statistically, superior control in the overall phase.

Historically, oral and intravenous formulations of granisetron and ondansetron have not demonstrated efficacy against delayed-phase CINV [4-8]. However, these results and those from a previously randomized, Phase III trial demonstrate that APF530 (granisetron injection, extended-release) provides sustained therapeutic concentrations of granisetron for $\geq 5$ days [18], translating into clinically meaningful benefits for patients receiving HEC. These results represent a shift from the view that all $5-\mathrm{HT}_{3} \mathrm{RAs}$ are equally effective for delayed-phase CINV following HEC.

Several studies have evaluated antiemetic therapy with HEC using combinations of a $5-\mathrm{HT}_{3}$ RA, NK-1 RA and corticosteroid. However, previous pivotal Phase III efficacy studies were of two-drug versus two-drug, or three-drug versus two-drug regimens [9,10,19,20,26-29]. Other registrational HEC trials evaluating antiemetics as part of a three-drug regimen (i.e., aprepitant, NEPA, rolapitant) involved two-drug regimen comparator arms only $\left(5-\mathrm{HT}_{3}\right.$ RA and dexamethasone) $[26,30]$. The MAGIC Trial represents the

Table 2. Secondary efficacy end points adjusted using the Hochberg method (modified intent-to-treat population).

\begin{tabular}{|c|c|c|c|c|c|}
\hline Parameter & $\begin{array}{l}\text { APF530 } n=450 \\
n(\%)\end{array}$ & $\begin{array}{l}\text { Ondansetron } n=452 \\
n(\%)\end{array}$ & $\begin{array}{l}\text { Treatment difference and } \\
\text { Hochberg-adjusted } 95 \% \mathrm{Cl} \\
\text { (APF530-ondansetron) }\end{array}$ & $\begin{array}{l}\text { Unadjusted } \\
\text { p-value }^{\dagger}\end{array}$ & $\begin{array}{l}\text { Hochberg- } \\
\text { adjusted } p \text {-value }\end{array}$ \\
\hline Overall phase CR rate & $263(58.4)$ & $239(52.9)$ & $5.6(-2.3-13.5)$ & 0.092 & 0.275 \\
\hline Delayed phase CC rate & $273(60.7)$ & $240(53.1)$ & $7.6(-0.6-15.8)$ & 0.022 & 0.088 \\
\hline Overall phase CC rate & $246(54.7)$ & $224(49.6)$ & $5.1(-2.3-12.6)$ & 0.123 & 0.247 \\
\hline Overall rate of no emesis & $370(82.2)$ & $358(79.2)$ & $3.0(-2.1-8.1)$ & 0.254 & 0.254 \\
\hline
\end{tabular}




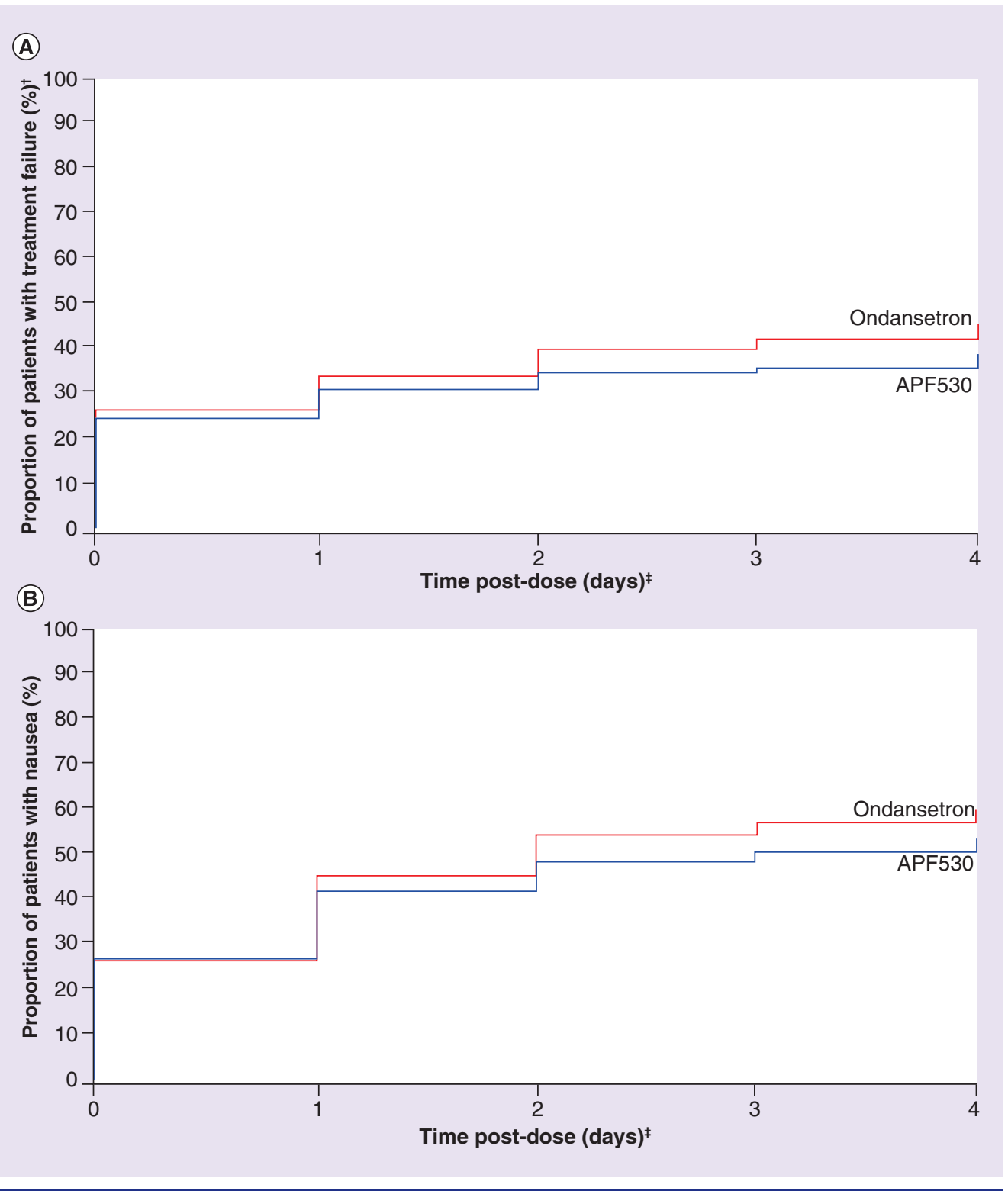

Figure 3. Time to treatment failure ${ }^{\dagger}(A)$ and time to first nausea episode (B).

${ }^{\dagger}$ Treatment failure is defined as emesis (vomiting or retching) or rescue medication use.

${ }^{\ddagger}$ Days elapsed since study drug administration, where $0=$ event or censored on study day 1 through 4 = event or censored on study day 5 .

first pivotal Phase III efficacy trial in HEC using a consensus guideline-recommended three-drug regimen in both arms. Moreover, this trial utilized ASCO 2011 guidelines for CINV emetogenicity classification. All patients were recruited from US community-based oncology centers, so results are highly representative of outcomes in that practice setting. Furthermore, the majority ( 80\%) of patients were women, representing a particularly high-risk group for CINV [31]. Lower-thanexpected CR rates observed in both treatment arms of this study were likely a consequence of the population having a greater proportion of high-risk individuals compared with a historical study evaluating a three-drug antiemetic regimen following HEC [24].

Following US FDA guidance, ondansetron was selected as the appropriate $5-\mathrm{HT}_{3}$ RA comparator because no $5-\mathrm{HT}_{3}$ RA had shown superiority to ondansetron in preventing delayed CINV following HEC. Although intravenous palonosetron is commonly used 
Table 3. Distribution of patients by frequency of nausea episodes (modified intent-to-treat population).

\begin{tabular}{|c|c|c|c|c|}
\hline Nausea episodes & $\begin{array}{l}\text { APF530 }(n=450), \\
n(\%)\end{array}$ & $\begin{array}{l}\text { Ondansetron }(n=452) \text {, } \\
n(\%)\end{array}$ & $\begin{array}{l}\text { Treatment difference } \\
(95 \% \mathrm{Cl}) ; \%\end{array}$ & $\mathrm{p}$-value \\
\hline \multicolumn{5}{|l|}{ Delayed: } \\
\hline$-\mathrm{n}$ & 425 & 418 & $7.0(0.6-13.4)$ & 0.032 \\
\hline$-0-2$ & $295(69.4)$ & $261(62.4)$ & & \\
\hline$-\geq 3$ & $130(30.6)$ & $157(37.6)$ & & \\
\hline \multicolumn{5}{|l|}{ Overall: } \\
\hline$-\mathrm{n}$ & 423 & 414 & $6.6(0.1-13.1)$ & 0.048 \\
\hline$-0-2$ & $276(65.2)$ & $243(58.7)$ & & \\
\hline$-\geq 3$ & $147(34.8)$ & $171(41.3)$ & & \\
\hline \multicolumn{5}{|l|}{ Acute: } \\
\hline$-n$ & 445 & 436 & $-1.4(-4.9-2.2)$ & 0.465 \\
\hline$-0-2$ & $406(91.2)$ & 404 (92.7) & & \\
\hline$-\geq 3$ & $39(8.8)$ & $32(7.3)$ & & \\
\hline
\end{tabular}

in this setting, it has not shown superiority in versus the standard of care intravenous $5-\mathrm{HT}_{3}$ a prespecified Phase III efficacy trial measure over ondansetron or any other $5-\mathrm{HT}_{3} \mathrm{RA}$ with HEC; consequently, palonosetron is not indicated for prevention of delayed CINV associated with HEC and is not preferred over any other $5-\mathrm{HT}_{3}$ RA by current antiemetic guidelines in that setting $[3,7,8,32]$.

The statistically significant $8.0 \%$ absolute treatment difference in CR (equating to a $14.2 \%$ relative difference) demonstrated by APF530

RA is similar in magnitude to treatment differences demonstrated in other trials where an NK-1 RA was added to the traditional two-drug regimen, leading to changes in guidelines and standard practice $[26,28,30,33]$. MAGIC is the first Phase III efficacy trial to demonstrate superiority of a 5-HT $\mathrm{HA}_{3} \mathrm{R}$ over another in preventing CINV following HEC in the presence of an NK-1 RA.

Cisplatin-associated CINV may be severe enough to require dose reductions or treatment

Table 4. Treatment-emergent adverse events occurring in $\geq 5 \%$ of patients (safety population).

System organ class/preferred term APF530 ( $n=456), n(\%)$

Ondansetron $(\mathrm{n}=459), \mathrm{n}(\%)$

Patients with at least 1 event

All grades

Grade $\geq 3$

All grades

Grade $\geq 3$

Preferred term:

- Neutropenia

- Constipation 413 (90.6) 89 (19.5) 411 (89.5) 89 (19.4)

- Nausea

26 (5.7)

$17(3.7)$

30 (6.5)

$24(5.2)$

- Diarrhea

$76(16.7)$

$1(0.2)$

$70(15.3)$

$0(0)$

- Dyspepsia

$40(8.8)$

$3(0.7)$

74 (16.1)

$4(0.9)$

- Fatigue

27 (5.9)

$3(0.7)$

35 (7.6)

0 (0)

- Decreased appetite

$95(20.8)$

$0(0)$

$32(7.0)$

$1(0.2)$

24 (5.3)

2 (0.4)

109 (23.7)

$3(0.7)$

- Dehydration

$23(5.0)$

$0(0)$

$23(5.0)$

0 (0)

- Headache

$56(12.3)$

5 (1.1)

- Dizziness

25 (5.5)

$3(0.7)$

18 (3.9)

$1(0.2)$

- Insomnia

21 (4.6)

$0(0)$

82 (17.9)

0 (0)

25 (5.4)

0 (0)

Injection-site reactions ${ }^{\dagger}$ :

- Bruising

191 (41.9)

$0(0)$

29 (6.3)

$0(0)$

- Pain

141 (30.9)

21 (4.6)

154 (33.6)

$25(5.4)$

- Nodule

$82(18.0)$

$3(0.7)$

163 (35.5)

7 (1.5)

- Erythema

77 (16.9)

$2(0.4)$

45 (9.8)

$2(0.4)$

- Swelling

45 (9.9)

$2(0.4)$

$127(27.7)$

$1(0.2)$

- Bleeding

$23(5.0)$

$2(0.4)$

$53(11.5)$

$0(0)$

${ }^{\dagger}$ Both treatment arms received Biochronomer tri(ethylene glycol) poly(orthoester) vehicle subcutaneous injection. 
discontinuation [3,34]. In a prespecified analysis of delayed-phase CR rates among patients in the cisplatin stratum, a $10.6 \%$ absolute treatment difference equating to a $19.4 \%$ relative treatment difference favoring APF530 indicates a pronounced clinical benefit within this particularly difficult-to-manage population. However, the study was not powered to detect statistical significance in this subset analysis.

The exploratory finding that a higher proportion of patients receiving APF530 experienced no or infrequent nausea is noteworthy, as they also had reduced rescue medication use. These promising results indicate a need for further study of APF530 effects on nausea control. Significantly higher rates of self-reported satisfaction with CINV therapy during the delayed phase were reported with APF530 versus ondansetron arms, suggesting that significantly improved CINV control with APF530 translates into increased patient satisfaction.

APF530 was generally well tolerated with no new or unexpected safety findings. Most TEAEs in both arms were mild or moderate. Most were ISRs (generally mild or moderate) and resolved by study end. Transient ISRs are not uncommon with subcutaneous injections such as APF530 [35,36].

Study limitations include short follow-up time, possibly resulting in lower frequency of TEAE resolution versus previous studies [18-20]. Furthermore, the double-dummy design resulted in ISRs in the ondansetron arm due to Biochronomer TEG-POE vehicle as the dummy APF530 injection. Nausea frequency, not a prespecified study end point, was a data-driven, post hoc, hypothesis-generating analysis.

\section{Conclusion}

Despite advances in antiemetic therapy, reports continue of poor CINV control, particularly in the delayed phase and in HEC such as cisplatinand AC-based regimens [37-39]. This study demonstrates APF530 superiority over ondansetron, as part of the guideline-recommended threedrug regimen, in controlling delayed-phase CINV following HEC. APF530 efficacy results from its extended-release Biochronomer delivery system, which provides sustained release of therapeutic concentrations of granisetron for $\geq 5$ days. These and previous findings in the MEC setting suggest that APF530 should be evaluated for inclusion in antiemetic clinical practice guidelines to provide effective CINV control following MEC and, in particular, to provide superior CINV control following HEC.

\section{Future perspective}

Despite considerable advances made in antiemetic therapy, CINV remains a clinical challenge, particularly in high-risk groups including younger patients, women and those receiving HEC. Control of delayed-phase CINV, nausea in particular, has been elusive.

In the next 5-10 years, we expect to see a renewed focus on nausea control in CINV research. We anticipate expanded research efforts toward identifying novel molecular and biologic targets for CINV control, and further investigation of known agents in the context of guideline-recommended therapy (i.e., cannabinoids). Finally, in the age of personalized medicine, we also anticipate efforts toward identifying new biomarkers for CINV that will facilitate individualized CINV prevention and treatment strategies.

\section{Supplementary data}

To view the supplementary data that accompany this paper please visit the journal website at: www.futuremedicine. com/doi/full/10.2217/fon-2016-0070

\section{Acknowledgements}

The authors would like to thank the many investigators and their clinical staff who made this study possible. Data analysis was performed by Dawn DuBois of EMB Statistical Solutions, LLC. Joan Rivers of Diamond Communications and Research, Inc, provided medical writing support and review for the Clinical Study Report for this study. Annemieke van Hest, Annet te Velde of AUTHOR! et al. $B V$ and Anna Perez of PM Biosolutions, Inc, provided medical writing support and review for the Summary of Clinical Safety and the Clinical Study Report.

\section{Financial \& competing interests disclosure}

ID Schnadig is employed by and has a leadership role at Compass Oncology, has been a consultantladvisor for Heron Therapeutics and Tesaro, and has received compensation for travel and accommodations from Heron Therapeutics and Tesaro. $N$ Gabrail reports a leadership role at ION Pharma, has received honoraria from Amgen, Boehringer Ingelheim, Celgene, Janssen, Johnson \& Johnson, Karyopharm Therapeutics, Sanofi and Taiho Pharmaceutical, has been a consultantladvisor for Heron Therapeutics and Karyopharm Therapeutics, has been part of a speaker's bureau for Amgen, Boehringer Ingelheim, and Johnson \& Johnson, has received research funding from Acerta, Amgen, Biothera, Boehringer Ingelheim, Celgene, Janssen, Johnson \& Johnson, Heron Therapeutics, 
Karyopharm Therapeutics, Sanofi, and Taiho Pharmaceutical, and has received compensation for travel and accommodations from Amgen, Biothera, Boehringer Ingelheim, Celgene, Janssen, Johnson \& Johnson, Karyopharm Therapeutics and Sanofi. RE Smith Jr has been a consultant/advisor for Cardinal Health and Flatiron Health. C Taylor has received research funding from Heron Therapeutics. LS Schwartzberg has been a consultant/advisor for Eisai, Helsinn and Tesaro, and has received research funding from Helsinn. W Cooper is employed by TFS, has stock or ownership from Amgen, Bristol-Myers Squibb, Merck and Pfizer, and has been a consultantladvisor for Heron Therapeutics through TFS. MC Mosier has been a consultantladvisor for Heron Therapeutics through EMB Statistical Solutions. JY Payne was employed by Heron Therapeutics during the time of study, and has stock or ownership from Heron Therapeutics and Johnson \& Johnson. MJ Klepper is employed and has a leadership role at Drug Safety Navigator, has stock or ownership from Drug Safety Navigator, and has been a consultantladvisor for Heron Therapeutics. JL Vacirca reports a leadership role at Caris Life Sciences and Flatiron Health, has stock or ownership from Caris Life Sciences and Flatiron Health, has received honoraria from Caris Life Sciences and Flatiron Health and has been a consultantladvisor for Heron Therapeutics and Spectrum Pharmaceuticals. The authors have no other relevant affiliations or financial involvement with any organization or entity with a financial interest in or financial conflict with the subject matter or materials discussed in the manuscript apart from those disclosed.

Medical writing support for this manuscript was provided by Joanna K Sandilos Rega of SciStrategy Communications, supported by Heron Therapeutics, Inc.

\section{Ethical conduct of research}

The authors state that they have obtained appropriate institutional review board approval or have followed the principles outlined in the Declaration of Helsinki for all human or animal experimental investigations. In addition, for investigations involving human subjects, informed consent has been obtained from the participants involved.

\section{EXECUTIVE SUMMARY}

- APF530 is a novel, extended-release granisetron formulation, providing sustained release of therapeutic concentrations for $\geq 5$ days.

- In a randomized, double-blind Phase III trial, a single subcutaneous dose of APF530 was noninferior to intravenous palonosetron in preventing acute chemotherapy-induced nausea and vomiting (CINV) after moderately emetogenic chemotherapy or highly emetogenic chemotherapy (HEC), and delayed CINV after moderately emetogenic chemotherapy, but was not superior to palonosetron in delayed CINV after HEC.

- This Phase III trial (MAGIC Trial) evaluated efficacy and safety of APF530 versus ondansetron, both administered with fosaprepitant and dexamethasone, for prevention of CINV after HEC. This is the first Phase III, registrational, efficacy trial comparing 5- $\mathrm{HT}_{3}$ receptor antagonists (RAs) in the presence of an NK-1 RA and dexamethasone for CINV prevention.

- The primary end point was reached; the proportion of patients with delayed-phase complete response was significantly greater with the APF530 versus ondansetron regimen, with an absolute treatment difference of $8.0 \%$ (95\% Cl: 1.7-14.4; $\mathrm{p}=0.014)$.

- Additionally, the APF530 regimen was associated with significant benefits in rescue medication use, patient satisfaction with antiemetic therapy and, in a post hoc analysis, nausea frequency.

- APF530 was generally well tolerated, with no new or unexpected safety findings.

- The superiority of the APF530 regimen over the ondansetron regimen reported here indicates that the extendedrelease formulation translates into a clinical benefit in the control of CINV after HEC, representing a shift from the view that $5-\mathrm{HT}_{3}$ RAs are equally effective in this setting.

\section{References}

Papers of special note have been highlighted as:

- of interest; $\bullet$ of considerable interest

1 Van Laar ES, Desai JM, Jatoi A. Professional educational needs for chemotherapy-induced nausea and vomiting (CINV): multinational survey results from 2,388 health care providers. Support. Care Cancer 23(1), 151-157 (2015).

2 Bloechl-Daum B, Deuson RR, Mavros P, Hansen M, Herrstedt J. Delayed nausea and vomiting continue to reduce patients' quality of life after highly and moderately emetogenic chemotherapy despite antiemetic treatment. J. Clin. Oncol. 24(27), 4472-4478 (2006).

3 Basch E, Prestrud AA, Hesketh PJ et al. Antiemetics: American Society of Clinical Oncology clinical practice guideline update. J. Clin. Oncol. 29(31), 4189-4198 (2011). 
- Updated American Society of Clinical Oncology (US) clinical practice guidelines for the prevention and treatment of CINV and reclassification of certain chemotherapy regimens according to emetogenic potential.

4 Aapro M, Molassiotis A, Dicato M et al. The effect of guideline-consistent antiemetic therapy on chemotherapy-induced nausea and vomiting (CINV): the Pan European Emesis Registry (PEER). Ann. Oncol. 23(8), 1986-1992 (2012).

5 Hilarius DL, Kloeg PH, Van Der Wall E, Van Den Heuvel JJ, Gundy CM, Aaronson NK. Chemotherapy-induced nausea and vomiting in daily clinical practice: a community hospital-based study. Support. Care Cancer 20(1), 107-117 (2012).

6 Geling O, Eichler HG. Should 5-hydroxytryptamine-3 receptor antagonists be administered beyond $24 \mathrm{~h}$ after chemotherapy to prevent delayed emesis? Systematic re-evaluation of clinical evidence and drug cost implications. J. Clin. Oncol. 23(6), 1289-1294 (2005).

7 Roila F, Herrstedt J, Aapro M et al. Guideline update for MASCC and ESMO in the prevention of chemotherapy- and radiotherapyinduced nausea and vomiting: results of the Perugia consensus conference. Ann. Oncol. 21(Suppl. 5), v232-v243 (2010).

- European clinical practice guidelines for the prevention and treatment of chemotherapy-induced nausea and vomiting (CINV).

8 NCCN Clinical Practice Guidelines in Oncology: Antiemesis - v2.2015. www.nccn.org

- National Comprehensive Cancer Network (US) clinical practice guidelines for the prevention and treatment of CINV.

9 Saito M, Aogi K, Sekine I et al. Palonosetron plus dexamethasone versus granisetron plus dexamethasone for prevention of nausea and vomiting during chemotherapy: a doubleblind, double-dummy, randomised, comparative Phase III trial. Lancet Oncol. 10(2), 115-124 (2009).

10 Aapro MS, Grunberg SM, Manikhas GM et al. A Phase III, double-blind, randomized trial of palonosetron compared with ondansetron in preventing chemotherapyinduced nausea and vomiting following highly emetogenic chemotherapy. Ann. Oncol. 17(9), 1441-1449 (2006).

11 Eisenberg P, Figueroa-Vadillo J, Zamora R et al. Improved prevention of moderately emetogenic chemotherapy-induced nausea and vomiting with palonosetron, a pharmacologically novel 5-HT3 receptor antagonist: results of a Phase III, single-dose trial versus dolasetron. Cancer 98(11), 2473-2482 (2003).

12 Gralla R, Lichinitser M, Van DV et al. Palonosetron improves prevention of chemotherapy-induced nausea and vomiting following moderately emetogenic chemotherapy: results of a double-blind randomized Phase III trial comparing single doses of palonosetron with ondansetron. Ann. Oncol. 14(10), 1570-1577 (2003).

13 Matsumoto K, Takahashi M, Sato K et al. Palonosetron or granisetron for prevention of CINV in patients with breast cancer receiving dexamethasone and fosaprepitant following anthracycline plus cyclophosphamide (AC) regimen. J. Clin. Oncol. 33(Suppl.), Abstract 9598 (2015).

14 Hashimoto H, Yamanaka T, Shimada Y et al. Palonosetron (PALO) versus granisetron (GRA) in the triplet regimen with dexamethasone (DEX) and aprepitant (APR) for preventing chemotherapy-induced nausea and vomiting (CINV) in patients (pts) receiving highly emetogenic chemotherapy (HEC) with cisplatin (CDDP): a randomized, double-blind, Phase III trial. J. Clin. Oncol. 31(Suppl.), Abstract 9621 (2013).

15 Ottoboni T, Gelder M, O’Boyle E. Biochronomer ${ }^{\mathrm{TM}}$ technology and the development of APF530, a sustained release formulation of granisetron. J. Exp. Pharmacol. 6, 15-21 (2014).

- Details of the technology used to develop APF530.

16 Heller J, Barr J. Biochronomer technology. Expert Opin. Drug Deliv. 2(1), 169-183 (2005).

17 Morrison D, Anderson A, Slama M et al. Phase 1 bioavailability study comparing 2 different subcutaneous routes of administration for APF530. Support. Care Cancer 23(Suppl.), Abstract 11-16-P (2015).

18 Gabrail N, Yanagihara R, Spaczynski M et al. Pharmacokinetics, safety, and efficacy of APF530 (extended-release granisetron) in patients receiving moderately or highly emetogenic chemotherapy: results of two Phase 2 trials. Cancer Manag. Res. 7, 83-92 (2015).

- Publication of two Phase II trials of APF530 in patients receiving moderately emetogenic chemotherapy or highly emetogenic chemotherapy.

19 Raftopoulos H, Boccia R, Cooper B, O'Boyle E, Gralla R. Slow-release granisetron
(APF530) vs palonosetron for chemotherapyinduced nausea/vomiting: analysis by ASCO emetogenicity criteria. Future Oncol. 11(18), 2541-2551 (2015).

20 Raftopoulos H, Cooper W, O’Boyle E, Gabrail N, Boccia R, Gralla

$\mathrm{RJ}$. Comparison of an extended-release formulation of granisetron (APF530) versus palonosetron for the prevention of chemotherapy-induced nausea and vomiting associated with moderately or highly emetogenic chemotherapy: results of a prospective, randomized, double-blind, noninferiority Phase 3 trial. Support. Care Cancer 23, 723-732 (2015).

- Primary publication of the APF530 Phase III noninferiority trial vs palonosetron in patients receiving moderately emetogenic chemotherapy or highly emetogenic chemotherapy.

21 Boccia RV, Cooper W, O'Boyle E. Sustained antiemetic responses with APF530 (sustainedrelease granisetron) during multiple cycles of emetogenic chemotherapy. J. Commun. Support. Oncol. 13, 38-46 (2015).

22 Varubi (rolapitant) tablets, for oral use, package insert. Tesaro, Inc., Waltham, MA, USA. www.accessdata.fda.gov

23 Akynzeo (netupitant and palonosetron) capsules, for oral use, prescribing information. Eisai, Inc., Woodcliff Lake, NJ, USA. www.akynzeo.com

24 Poli-Bigelli S, Rodrigues-Pereira J, Carides $\mathrm{AD}$ et al. Addition of the neurokinin 1 receptor antagonist aprepitant to standard antiemetic therapy improves control of chemotherapy-induced nausea and vomiting. Results from a randomized, double-blind, placebo-controlled trial in Latin America. Cancer 97(12), 3090-3098 (2003).

25 Hochberg Y. A sharper Bonferroni procedure for multiple tests of significance. Biometrika 75(4), 800-802 (1988).

26 Aapro M, Rugo H, Rossi Get al. A randomized Phase III study evaluating the efficacy and safety of NEPA, a fixed-dose combination of netupitant and palonosetron, for prevention of chemotherapy-induced nausea and vomiting following moderately emetogenic chemotherapy. Ann. Oncol. 25(7), 1328-1333 (2014).

27 Rapoport BL. Efficacy of a triple antiemetic regimen with aprepitant for the prevention of chemotherapy-induced nausea and vomiting: effects of gender, age, and region. Curr. Med. Res. Opin. 30(9), 1875-1881 (2014). 

and safety of NEPA, an oral combination of netupitant and palonosetron, for prevention of chemotherapy-induced nausea and vomiting following highly emetogenic chemotherapy: a randomized dose-ranging pivotal study. Ann. Oncol. 25(7), 1340-1346 (2014).

29 Rapoport BL, Jordan K, Boice JA et al. Aprepitant for the prevention of chemotherapy-induced nausea and vomiting associated with a broad range of moderately emetogenic chemotherapies and tumor types: a randomized, double-blind study. Support. Care Cancer 18(4), 423-431 (2010).

30 Rapoport BL, Chasen MR, Gridelli C et al. Safety and efficacy of rolapitant for prevention of chemotherapy-induced nausea and vomiting after administration of cisplatin-based highly emetogenic chemotherapy in patients with cancer: two randomised, active-controlled, double-blind, Phase 3 trials. Lancet Oncol. 16(9), 1079-1089 (2015).
31 Navari RM. Pharmacological management of chemotherapy-induced nausea and vomiting: focus on recent developments. Drugs 69(5), 515-533 (2009)

32 Aloxi (palonosetron $\mathrm{HCl}$ ) injection for intravenous use, prescribing information. Eisai, Inc., Woodcliff Lake, NJ, USA (2014). www.aloxi.com/docs/pdf/pi.pdf

33 Schnadig I, Modiano MR, Poma A, Hedley ML, Martell RE, Schwartzberg LS. Phase 3 trial results for rolapitant, a novel NK-1 receptor antagonist, in the prevention of chemotherapy-induced nausea and vomiting (CINV) in subjects receiving moderately emetogenic chemotherapy (MEC). J. Clin. Oncol. 32(Suppl.), Abstract 9633 (2014).

34 Platinol (cisplatin for injection, USP), prescribing information. Bristol-Myers Squibb Company, Princeton, NJ, USA. www.accessdata.fda.gov Depo-Provera CI (medroxyprogesterone acetate) injectable suspension, for intramuscular use, prescribing information. Pfizer, Inc., New York, NY, USA. http://labeling.pfizer.com
36 Lupron Depot (leprolide acetate for depot suspension), package insert. AbbVie, Inc., North Chicago, IL, USA. www.rxabbvie.com

37 Aoki S, Iihara $\mathrm{H}$, Nishigaki $\mathrm{M}$ et al. Difference in the emetic control among highly emetogenic chemotherapy regimens: Implementation for appropriate use of aprepitant. Mol. Clin. Oncol. 1(1), 41-46 (2013).

38 Longo F, Mansueto G, Lapadula V et al. Palonosetron plus 3-day aprepitant and dexamethasone to prevent nausea and vomiting in patients receiving highly emetogenic chemotherapy. Support. Care Cancer 19(8), 1159-1164 (2011).

39 Abe M, Hirashima Y, Kasamatsu Y et al. Efficacy and safety of olanzapine combined with aprepitant, palonosetron, and dexamethasone for preventing nausea and vomiting induced by cisplatin-based chemotherapy in gynecological cancer: KCOG-G1301 Phase II trial. Support. Care Cancer 24(2), 675-682 (2015). 